\title{
Lack of Prognostic Impact of Adjuvant Radiation on Oncologic Outcomes in Elderly Women with Breast Cancer
}

\author{
Shapour Omidvari ${ }^{1}$, Abdolrasoul Talei ${ }^{1}$, Sedigheh Tahmasebi ${ }^{1}$, Leila \\ Moaddabshoar ${ }^{2}$, Maliheh Dayani ${ }^{3}$, Ahmad Mosalaei ${ }^{4}$, Niloofar Ahmadloo ${ }^{3}$, \\ Mansour Ansari ${ }^{3}$, Mohammad Mohammadianpanah ${ }^{5 *}$
}

\begin{abstract}
Background: Radiotherapy plays an important role as adjuvant treatment in locally advanced breast cancer and in those patients who have undergone breast-conserving surgery. This study aimed to investigate the prognostic impact of adjuvant radiation on oncologic outcomes in elderly women with breast cancer. $\underline{\text { Materials }}$ and Methods: In this retrospective study, we reviewed and analyzed the characteristics, treatment outcome and survival of elderly women (aged $\geq 60$ years) with breast cancer who were treated and followed-up between 1993 and 2014. The median follow up for the surviving patients was 38 (range 3-207) months. Results: One hundred and seventy-eight patients with a median age of 74 (range 60-95) years were enrolled in the study. Of the total, 60 patients received postoperative adjuvant radiation (radiation group) and the remaining 118 did not (control group). Patients in the radiation group were significantly younger than those in the control group (P value $=0.004)$. In addition, patients in radiation group had higher node stage $(P$ value $<0.001)$ and disease stage $(P=0.003)$ and tended to have higher tumor grade $(P=0.031)$ and received more frequent $(P$ value $<0.001)$ adjuvant and neoadjuvant chemotherapy compared to those in the control group. There was no statistically significant difference between two groups regarding the local control, disease-free survival and overall survival rates. Conclusions: In this study, we did not find a prognostic impact for adjuvant radiation on oncologic outcomes in elderly women with breast cancer.
\end{abstract}

Keywords: Elderly women - breast cancer - adjuvant radiation - prognosis - survival

Asian Pac J Cancer Prev, 16 (17), 7813-7818

\section{Introduction}

Radiotherapy has a well established role as adjuvant treatment in locally advanced breast cancer and in those patients who have undergone breast conserving surgery (Guire et al., 2007; Tinterri et al., 2009; Phua et al., 2010; Yavas et al., 2013). However, this is a time consuming treatment, has a high cost and can be associated with painful side effects in the majority of patients. Additionally, Breast radiotherapy can expose heart to ionizing radiation which increases the rate of coronary heart diseases (Darby et al., 2013; Guan et al., 2015).

Breast cancer in elderly postmenopausal women tend to be less biologically aggressive and to have favorable outcome compared to younger patients. Patients younger than 40 years have higher rates of local recurrence than older patients (Zhou and Recht, 2004; Oran et al., 2014). Because of other associated diseases, older patients with breast cancer are less likely to receive standard treatments and radiotherapy may be omitted in this age group and even results in a better quality of life (Yancik et al., 2001;
Tinterri et al., 2009; Wang et al., 2009; Vrana et al., 2014; Palta et al., 2015). Radiotherapy is also less likely to be used in old patients with estrogen receptor positive breast cancer (Rutter et al., 2015). To evaluate the role of radiotherapy in old patients, we compare the results of treatment between patients who received postoperative radiotherapy with those who underwent surgery alone.

\section{Materials and Methods}

In this study, we retrospectively reviewed and analyzed the characteristics, treatment outcome and survival of elderly women aged $\geq 60$ years with newly histologically proven invasive breast adenocarcinoma that were treated and followed-up between 1993 and 2014. Patients with other epithelial pathologies such as squamous cell carcinoma, or non-epithelial tumors such as lymphomas and sarcomas were excluded. Tumor staging was performed using the seventh edition of American Joint Committee on Cancer TNM (AJCC) staging system. Clinical staging was carried out using imaging studies for

${ }^{1}$ Breast Diseases Research Center, ${ }^{3}$ Department of Radiation Oncology, ${ }^{4}$ Shiraz Institute for Cancer Research, Medical School, ${ }^{5}$ Colorectal Research Center, Shiraz University of Medical Sciences, Shiraz, ${ }^{2}$ Department of Radiation Oncology, Hamedan University of Medical Sciences, Hamedan, Iran*For correspondence: mohpanah@gmail.com 
all the patients before starting neoadjuvant treatments. Preliminary evaluation included comprehensive history and physical examination, bilateral mammography, chest radiography, echocardiography, complete blood cell count (CBC), and liver and renal function studies. Further investigation including whole body bone scintigraphy, CT scan of the chest, abdomen, and pelvis and brain MRI was performed in patients with stage III-IV and selected symptomatic cases. All patients but 4 underwent modified radical mastectomy $(\mathrm{n}=115)$ or conserving breast surgery $(n=59)$. Adjuvant radiotherapy consisted of conventional external beam radiation using $6 \mathrm{MV}$ megavoltage linear accelerator photons. The radiation portals were composed of the breast or chest wall fields in all patients and supraclavicular and posterior axillary fields in node positive cases. The patients received a total dose of 45-50.4 Gy with a daily fraction of 1.8-2 Gy, with five fractions per week. Adjuvant or neoadjuvant chemotherapy consisted of a median 6 (range 4-8) cycles of one of the following regimens: 1- 5-Fluorouracil (5-FU), methotrexate and cyclophosphamide (CMF regimen), 2- 5-FU, doxorubicin and cyclophosphamide (CAF regimen), 3- 5-FU, epirubicin and cyclophosphamide (CEF regimen), 4doxorubicin and cyclophosphamide followed by paclitaxel $(\mathrm{AC} \rightarrow \mathrm{P}$ regimen) every three weeks. Patients with estrogen receptor (ER) and/or progesterone receptor (PR) positive breast cancer received hormone therapy with tamoxifen or letrozole for 5 years.

\section{Statistics}

Clinical and pathological variables were analyzed using the IBM SPSS statistics version 21 software. Categorical variables of tumor characteristics (such as tumor grade, stage and hormone receptor status) and treatment modalities (such as type of surgery, radiotherapy, chemotherapy and hormone therapy) were compared by using chi-square tests and for continuous variables such as patients' age and total number dissected lymph nodes Student $t$ tests was used. Local control rate was defined as the proportion of patients who were free of locoregional recurrent disease at 10 years. Disease-free survival rate was defined as the percentage of patients who were free of breast cancer at 10 years; an overall survival rate was defined as the percentage of patients who were alive at 10 years. The survival durations were measured from the date of initial treatment till the events of locoregional recurrence (locoregional control), any type of treatment relapse (disease free survival), death from any reason (overall survival) or the last follow-up. The significance of differences in survival was evaluated using the logrank test. Kaplan-Meier was used to estimate survival experience of the different groups of the prognostic factors. Multiple-covariate analysis was performed using the stepwise regression hazards regression model. The hazard ratio (HR) for death, with the $95 \%$ confidence interval (CI) was calculated for the variable groups. The log-rank test was used to compare treatment results in each variable group. All $\mathrm{P}$ values were 2 -tailed and $\mathrm{P}$ values less than 0.05 were considered statistically significant.

\section{Results}

\section{Patients and tumor characteristics}

One hundred and seventy-eight patients were enrolled in the study. Sixty patients (radiation group) received postoperative adjuvant radiation and remaining 118 patients (control group) not received adjuvant radiation. The median age of all patients was 74 years (range 6095 years). Patients in radiation group were significantly younger than those in the control group ( $\mathrm{P}$ value $=0.004)$. The distribution of tumor stage was as follows: stage I-II 50 cases $(83 \%)$ and stage III-IV 10 cases (17\%) in radiation group; and stage I-II 104 cases (88\%) and stage III-IV 14 cases (12\%) in control group. We found a statistically significant difference regarding the node stage ( $\mathrm{P}$ value $<0.001)$ and disease stage $(\mathrm{P}=0.003)$ distribution between radiation and control groups. Patients in radiation group had more advanced node stage and disease stage compared to those in the control group. Additionally, patients in radiation group tended to have higher rate of grade II-III $(\mathrm{P}=0.031)$ and the use of neoadjuvant chemotherapy ( $\mathrm{P}$ value $<0.001$ ) compared to those in the control group. The numbers of total dissected lymph nodes were similar between treatment groups. As well, there was a no statistically significant difference regarding the status of estrogen and progesterone hormone receptors and Her 2 overexpression between radiation and control groups (Table 1).

\section{Oncologic outcomes}

After a median follow up of 38 (range 3-207) months for the surviving patients, the 5-year local control (LC), disease free survival (DFS) and overall survival (OS) rates were $82.6 \%, 67.7 \%$, and $69.4 \%$, respectively. The 10-year local control (LC), disease free survival (DFS) and overall survival (OS) rates were $74.6 \%, 32.8 \%$, and $69.4 \%$, respectively. On univariate analysis, node stage (log rank test, $\mathrm{P}<0.001$ ), and stage of disease (log rank test, $\mathrm{P}=0.003$ ) were found to be prognostic factors for LC, and DFS. Table 2 represents the univariate analysis of prognostic

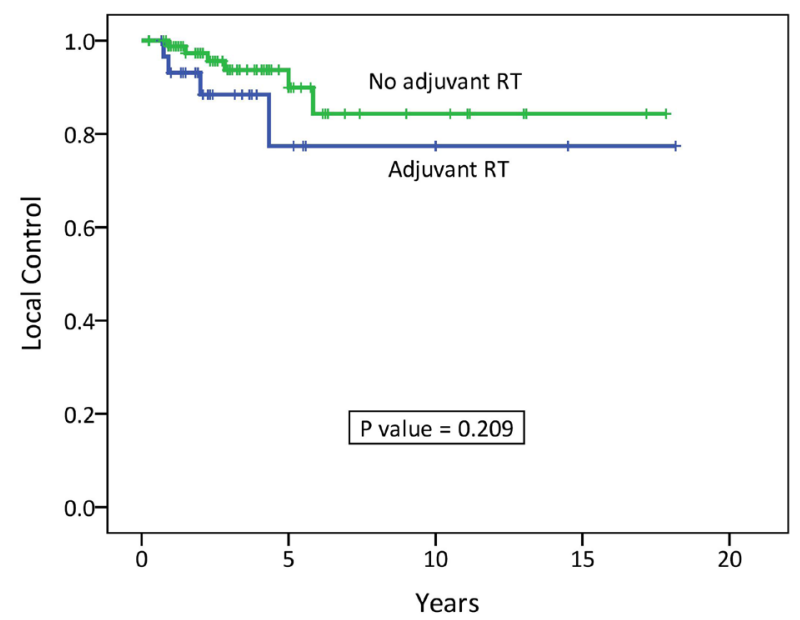

Figure 1. Kaplan-Meier Survival Analysis of Local Control Categorized According to the use of Adjuvant Radiation in 178 Elderly Patients with Stage I-II Breast Cancer 
Lack of Prognostic Impact of Adjuvant Radiation on Oncologic Outcomes in Elderly Women with Breast Cancer

Table 1. Clinical and pathological characteristics

\begin{tabular}{|c|c|c|c|}
\hline \multirow[t]{2}{*}{ Variable } & \multicolumn{2}{|c|}{ Adjuvant radiation } & \multirow{2}{*}{$\begin{array}{l}\text { P Value } \\
\mathrm{d}\end{array}$} \\
\hline & Received & Not received & \\
\hline Total & 60 & 118 & \\
\hline Age $($ mean \pm SD $)$ & $72.5 \pm 4.5$ & $75.3 \pm 6.5$ & 0.004 \\
\hline Type of surgery & & & 0.737 \\
\hline MRM & 41 & 74 & \\
\hline BCS & 19 & 40 & \\
\hline Tumor stage & & & 0.486 \\
\hline $\mathrm{T} 1-2$ & 50 & 104 & \\
\hline T3-4 & 10 & 14 & \\
\hline Node stage & & & $<0.001$ \\
\hline N0-1 & 33 & 98 & \\
\hline $\mathrm{N} 2-3$ & 27 & 20 & \\
\hline Dissected L.N (mean \pm SD) & $15.6 \pm 9.6$ & $12.8 \pm 9.5$ & 0.082 \\
\hline Involved node $($ mean $\pm S D)$ & $4.9 \pm 6.2$ & $3.0 \pm 6.8$ & 0.104 \\
\hline Disease stage & & & 0.003 \\
\hline I-II & 30 & 86 & \\
\hline III-IV & 30 & 32 & \\
\hline Tumor grade & & & 0.031 \\
\hline I & 11 & 43 & \\
\hline II & 41 & 58 & \\
\hline III & 8 & 17 & \\
\hline Estrogen receptor & & & 0.372 \\
\hline Positive & 41 & 89 & \\
\hline Negative & 19 & 29 & \\
\hline Progesterone receptor & & & 0.516 \\
\hline Positive & 34 & 74 & \\
\hline Negative & 26 & 44 & \\
\hline Her2 & & & 0.553 \\
\hline Positive & 10 & 25 & \\
\hline Negative & 44 & 75 & \\
\hline Unknown & 6 & 18 & \\
\hline Neoadjuvant ChT & & & $<0.001$ \\
\hline Received & 15 & 5 & \\
\hline Not received & 45 & 113 & \\
\hline
\end{tabular}

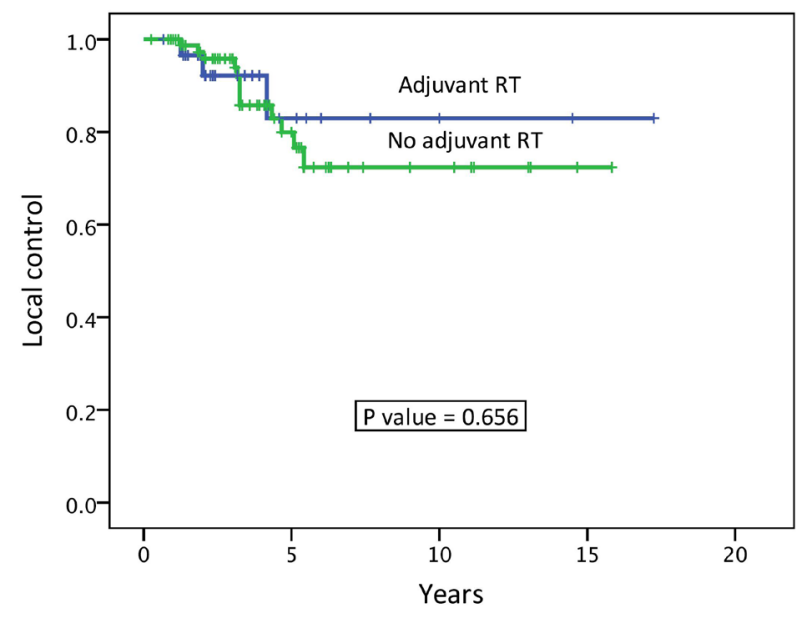

Figure 2. Kaplan-Meier Survival Analysis of Local Control Categorized According to the use of Adjuvant Radiation in 178 Elderly Patients with Stage III-IV Breast Cancer

factors for 10-year local control rate in the 178 patients with breast cancer. Additionally, we found the same results using the stratified Log-Rank test of prognostic factors for 10-year local control rate (Table 3). Accordingly, we found a non significant better local control rate in stage
Table 2. Univariate analysis of prognostic factors for 10-year local control rate in the 178 patients with breast cancer

\begin{tabular}{|c|c|c|c|c|}
\hline $\begin{array}{l}\text { Variable } \\
\text { local control rate }(\%)\end{array}$ & 10-year & $\mathrm{P}$ valuea & HR & $95 \% \mathrm{CI}$ \\
\hline Age & & 0.42 & 1.38 & $0.63-3.02$ \\
\hline$\leq 73$ years & 79.8 & & & \\
\hline$>73$ years & 67.6 & & & \\
\hline Tumor stage & & 0.163 & 1.92 & $0.76-4.81$ \\
\hline $\mathrm{T} 1-2$ & 79 & & & \\
\hline T3-4 & 51.2 & & & \\
\hline Node stage & & 0.001 & 4 & $1.81-8.86$ \\
\hline N0-1 & 81.3 & & & \\
\hline $\mathrm{N} 2-3$ & 52.7 & & & \\
\hline Dissected L.N & & 0.594 & 1.27 & $0.52-3.07$ \\
\hline$\leq 14$ & 74.8 & & & \\
\hline$>14$ & 82.9 & & & \\
\hline Involved node & & 0.638 & 1.26 & $0.47-3.37$ \\
\hline$\leq 3$ & 81.1 & & & \\
\hline$>3$ & 73 & & & \\
\hline Disease stage & & 0.002 & 3.34 & $1.49-7.46$ \\
\hline I-II & 82.4 & & & \\
\hline III-IV & 58.4 & & & \\
\hline Tumor grade & & 0.222 & 1.75 & $0.70-4.38$ \\
\hline I & 79.2 & & & \\
\hline II-III & 72.7 & & & \\
\hline Estrogen receptor & & 0.772 & 1.14 & $0.47-2.75$ \\
\hline Positive & 71.8 & & & \\
\hline Negative & 80.4 & & & \\
\hline Progesterone receptor & & 0.439 & 1.35 & $0.62-2.95$ \\
\hline Positive & 78 & & & \\
\hline Negative & 69.2 & & & \\
\hline Her2 & & 0.489 & 1.93 & $0.48-7.64$ \\
\hline Positive & 55.7 & & & \\
\hline Negative & 69.3 & & & \\
\hline Unknown & 86.7 & & & \\
\hline Neoadjuvant ChT & & 0.717 & 1.3 & $0.30-5.59$ \\
\hline Received & 85.5 & & & \\
\hline Not received & 74.3 & & & \\
\hline Adjuvant RT & & 0.453 & 1.35 & $0.61-3.01$ \\
\hline Received & 74.5 & & & \\
\hline Not received & 75.7 & & & \\
\hline Overall & 74.6 & & & \\
\hline
\end{tabular}

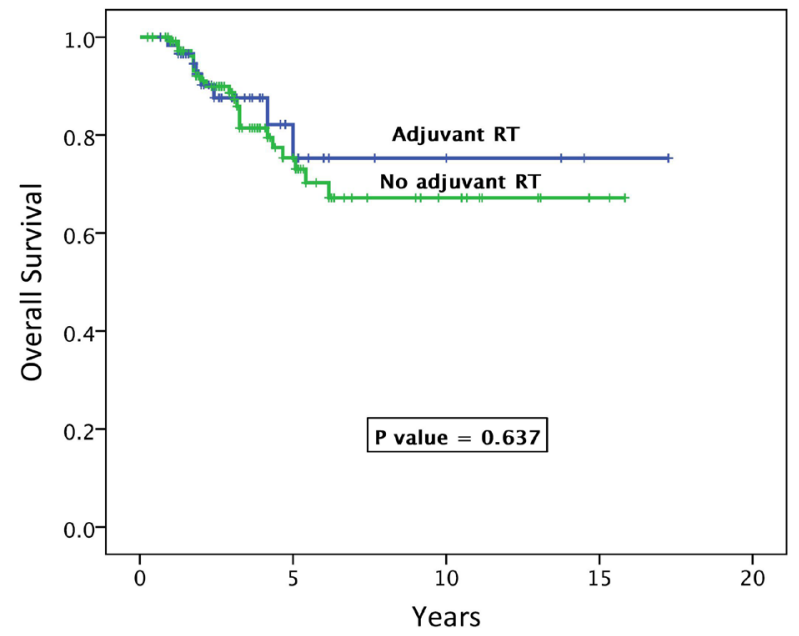

Figure 3. Kaplan-Meier Survival Analysis of Overall Survival Categorized According to the use of Adjuvant Radiation in 178 Elderly Patients with Breast Cancer 
Table 3. Stratified Log-Rank test of prognostic factors for 10-year local control rate in the 178 patients with breast cancer

\begin{tabular}{|c|c|c|c|c|c|}
\hline \multirow[t]{2}{*}{ Variable } & \multicolumn{2}{|c|}{10 -year local control rate $(\%)$} & \multirow[t]{2}{*}{$\mathrm{P}$ valuea } & \multirow[t]{2}{*}{$\mathrm{HR}$} & \multirow[t]{2}{*}{$95 \% \mathrm{CI}$} \\
\hline & With adjuvant RT & Without adjuvant RT & & & \\
\hline Age & & & 0.453 & 1.36 & $0.60-3.10$ \\
\hline$\leq 73$ years & 81.8 & 79 & & & \\
\hline$>73$ years & 66 & 71.6 & & & \\
\hline Tumor stage & & & 0.37 & 1.56 & $0.58-4.21$ \\
\hline T1-2 & 78.2 & 79.4 & & & \\
\hline T3-4 & 56.3 & 50 & & & \\
\hline Node stage & & & 0.001 & 4 & $1.67-9.59$ \\
\hline N0-1 & 78.3 & 82.3 & & & \\
\hline $\mathrm{N} 2-3$ & 67.9 & 41.8 & & & \\
\hline Dissected L.N & & & 0.44 & 1.43 & $0.57-3.60$ \\
\hline$\leq 14$ & 84 & 70 & & & \\
\hline$>14$ & 46.4 & 94.6 & & & \\
\hline Involved node & & & 0.524 & 1.37 & $0.51-3.72$ \\
\hline$\leq 3$ & 78.4 & 82.4 & & & \\
\hline$>3$ & 40 & 79.7 & & & \\
\hline Disease stage & & & 0.006 & 3.07 & $1.33-7.07$ \\
\hline I-II & 77.4 & 84.3 & & & \\
\hline III-IV & 69.3 & 54.4 & & & \\
\hline Tumor grade & & & 0.19 & 1.94 & $0.70-5.30$ \\
\hline I & 83.3 & 79.9 & & & \\
\hline II-III & 74.8 & 72.6 & & & \\
\hline Estrogen receptor & & & 0.572 & 1.3 & $0.51-5.31$ \\
\hline Positive & 65.2 & 75.6 & & & \\
\hline Negative & 94.7 & 74.3 & & & \\
\hline Progesterone receptor & & & 0.204 & 1.67 & $0.74-3.76$ \\
\hline Positive & 78 & 79.4 & & & \\
\hline Negative & 71 & 69.6 & & & \\
\hline Her2 & & & 0.619 & 1.81 & $0.51-6.41$ \\
\hline Positive & 64.3 & 60 & & & \\
\hline Negative & 79.7 & 68.1 & & & \\
\hline Unknown & 66.7 & 93.8 & & & \\
\hline Neoadjuvant ChT & & & 0.356 & 1.82 & $0.39-8.40$ \\
\hline Received & 87.5 & 80 & & & \\
\hline Not received & 70.3 & 75.8 & & & \\
\hline Overall & 74.5 & 75.7 & 0.475 & 1.35 & $0.58-3.11$ \\
\hline
\end{tabular}

I-II in control group compared to radiation group (Figure 1); and a non significant better local control rate in stage III-IV in radiation group compared to control group (Figure 2). Regarding overall survival, tumor stage (log rank test, $\mathrm{P}=0.016$ ), node stage (log rank test, $\mathrm{P}=0.001$ ), and stage of disease ( $\log$ rank test, $\mathrm{P}=0.013$ ) were found to be prognostic factors for overall survival. However, adjuvant radiation did not have a significant impact on overall survival (Figure 3).

On multivariate analysis, only node stage was found to be independent prognostic factors for $\mathrm{LC}$ rate. Higher node (N2-3) stage $[\mathrm{HR}=4.36,95 \% \mathrm{CI}=1.75-10.86, \mathrm{P}=0.002]$ had a negative influence on LC rate. Regarding DFS, Her2 positivity $(\mathrm{HR}=5.10,95 \% \mathrm{CI}=1.61-16.10, \mathrm{P}=0.005]$, and higher node $(\mathrm{N} 2-3)$ stage $[\mathrm{HR}=3.55,95 \% \mathrm{CI}=1.75-10.86$, $\mathrm{P}<0.001]$ had a negative influence on DFS. Additionally, higher node (N2-3) stage $[\mathrm{HR}=3.69,95 \% \mathrm{CI}=1.67-8.14$, $\mathrm{P}=0.001]$ was found to be an independent prognostic factors for OS. Accordingly, we did not find a prognostic impact for adjuvant radiation on oncologic outcomes in elderly patients with breast cancer.

\section{Discussion}

Some studies confirmed that adjuvant systemic therapy including chemotherapy and/or hormone therapy significantly reduces locoregional recurrence rate in patients treated with breast-conserving surgery compared to those treated with conservative surgery alone; however, it is unclear whether this treatment strategy can replace the need for radiotherapy following conservative surgery alone (Fisher et al., 1996a; Fisher et al., 1996b; Dalberg et al., 1998). In NSABP trial B-13, adjuvant chemotherapy significantly reduced the eight-year local recurrence from $13.4 \%$ to $2.6 \%$ in women with nodenegative, estrogen receptor negative invasive tumors compared to local treatment alone (Fisher et al., 1996b). In NSABP trial B-14, adjuvant hormone therapy using tamoxifen in women with node-negative, ER-positive tumors significantly reduced the rate of 10-year local recurrence from $14.7 \%$ to $4.3 \%$ compared to placebo arm (Fisher et al., 1996a). In addition, similar findings were observed in the Stockholm Breast Cancer Study Group. The ten-year local recurrence rate was significantly less 
(3 versus 12 percent) in tamoxifen arm compared to placebo arm in women with node-negative breast cancer following conservative surgery (Dalberg et al., 1998). In another study in the German Breast Cancer Study Group (GBSG)-V trial, early stage low-risk breast cancer patients undergoing breast conserving surgery were randomly assigned to RT or not, and to tamoxifen or not. This study showed a benefit for both RT and tamoxifen in reducing local recurrence rates compared to conserving surgery alone; however, there was no significant difference between RT and tamoxifen in terms of local recurrence rate $(5.3 \%$ for RT versus $7.5 \%$ for tamoxifen) (Winzer et al., 2010).

The omission of RT is particularly interesting subject in elderly women. Several randomized trials investigated the prognostic impact of adjuvant RT on oncologic outcome in elderly women with breast cancer following breast-conserving surgery. Overall, the findings of these studies support that in selected low risk elderly women (over the age of 70), treatment with adjuvant endocrine therapy alone provides a reasonable outcome (Fisher et al., 2002; Fyles et al., 2004; Potter et al., 2007)

Richard Pötter et al. reported on 869 women with mean age of 66 years with favorable early stage breast cancer who randomly assigned to receive or not receive post-lumpectomy radiotherapy between 1996 and 2004. They found that breast radiotherapy plus tamoxifen or anastrazole results in significant reduction in local and overall recurrence. In that study all patients had estrogen or progesterone receptor positive tumors with $3 \mathrm{~cm}$ or less diameter (Potter et al., 2007).

Hughes et al reported on 636 patients (70 years of age or older) with stage one estrogen receptor positive breast cancer who received or not received post-lumpectomy radiotherapy plus tamoxifen. Although there was a significant difference between two groups regarding locoregional recurrence, the rates of mastectomy, distant metastases and overall survival were comparable in two groups (Hughes et al., 2004).

Vrana et al. suggested that omission of radiotherapy in a selected group of patients 70 years of age or older with breast cancer may be safe and results in a better quality of life (Vrana et al., 2014).

Cancer and Leukemia Group B 9343 study revealed a statistically significant better locoregional control with tamoxifen plus radiotherapy versus tamoxifen alone after lumpectomy in women with early stage breast cancer and $\geq 70$ years of age. No clear benefit was found for addition of radiotherapy in that study regarding distant disease free and overall survival. Moreover, only $3 \%$ of patients died as a result of their cancer. The authors concluded that radiotherapy may be omitted after lumpectomy in old women ( $\geq 70$ years) with stage one hormone receptor positive breast cancer (Hughes et al., 2013).

Our study showed no benefit for the addition of radiotherapy after surgery in old patients with breast cancer. Although in subgroup analysis those patients with higher stage of disease had a statistically non-significant better local control with radiotherapy, patients with early stage disease had no benefit with adjuvant radiotherapy. Despite the limitations of our study including the small number of patients and the heterogeneity of cases in terms of patients' mean age, tumor stage, and ER and PR status, the findings of this study is in consistent with previous large studies.

\section{References}

Dalberg K, Johansson H, Johansson U, et al (1998). A randomized trial of long term adjuvant tamoxifen plus postoperative radiation therapy versus radiation therapy alone for patients with early stage breast carcinoma treated with breast-conserving surgery. stockholm breast cancer study group. Cancer, 82, 2204-11.

Darby SC, Ewertz M, McGale P, et al (2013). Risk of ischemic heart disease in women after radiotherapy for breast cancer. N Engl J Med, 368, 987-98.

Fisher B, Bryant J, Dignam JJ, et al (2002). Tamoxifen, radiation therapy, or both for prevention of ipsilateral breast tumor recurrence after lumpectomy in women with invasive breast cancers of one centimeter or less. J Clin Oncol, 20, 4141-9.

Fisher B, Dignam J, Bryant J, et al (1996a). Five versus more than five years of tamoxifen therapy for breast cancer patients with negative lymph nodes and estrogen receptor-positive tumors. J Natl Cancer Inst, 88, 1529-42.

Fisher B, Dignam J, Mamounas EP, et al (1996b). Sequential methotrexate and fluorouracil for the treatment of nodenegative breast cancer patients with estrogen receptornegative tumors: eight-year results from National Surgical Adjuvant Breast and Bowel Project (NSABP) B-13 and first report of findings from NSABPB-19 comparing methotrexate and fluorouracil with conventional cyclophosphamide, methotrexate, and fluorouracil. J Clin Oncol, 14, 1982-92.

Fyles AW, McCready DR, Manchul LA, et al (2004). Tamoxifen with or without breast irradiation in women 50 years of age or older with early breast cancer. $N$ Engl J Med, 351,963-70.

Guan H, Dong YL, Ding LJ, et al (2015). Morphological factors and cardiac doses in whole breast radiation for left-sided breast cancer. Asian Pac J Cancer Prev, 16, 2889-94.

Hughes KS, Schnaper LA, Bellon JR, et al (2013). Lumpectomy plus tamoxifen with or without irradiation in women age 70 years or older with early breast cancer: long-term follow-up of CALGB 9343. J Clin Oncol, 31, 2382-7.

Hughes KS, Schnaper LA, Berry D, et al (2004). Lumpectomy plus tamoxifen with or without irradiation in women 70 years of age or older with early breast cancer. $N$ Engl $J$ Med, 351, 971-7.

McGuire SE, Gonzalez-Angulo AM, Huang EH, et al (2007). Postmastectomy radiation improves the outcome of patients with locally advanced breast cancer who achieve a pathologic complete response to neoadjuvant chemotherapy. Int J Radiat Oncol Biol Phys, 68, 1004-9.

Oran ES, Yankol Y, Soybir GR, et al (2014). Distinct postsurgical management in young and elderly breast cancer patients results in equal survival rates. Asian Pac J Cancer Prev, 15, 7843-7.

Palta M, Palta P, Bhavsar NA, et al (2015). The use of adjuvant radiotherapy in elderly patients with early-stage breast cancer: changes in practice patterns after publication of cancer and leukemia group B 9343. Cancer, 121, 188-93.

Phua CE, Bustam AZ, Yip CH, et al (2010). Prognostic factors for elderly breast cancer patients in University Malaya Medical Centre, Malaysia. Asian Pac J Cancer Prev, 11, 1205-11.

Potter R, Gnant M, Kwasny W, et al (2007). Lumpectomy plus tamoxifen or anastrozole with or without whole breast irradiation in women with favorable early breast cancer. Int J Radiat Oncol Biol Phys, 68, 334-40. 
Rutter CE, Lester-Coll NH, Mancini BR, et al (2015). The evolving role of adjuvant radiotherapy for elderly women with early-stage breast cancer. Cancer.

Tinterri C, Gatzemeier W, Zanini V, et al (2009). Conservative surgery with and without radiotherapy in elderly patients with early-stage breast cancer: a prospective randomised multicentre trial. Breast, 18, 373-7.

Vrana D, Gatek J, Lukesova L, et al (2014). Omission of adjuvant radiation therapy in elderly patients with low risk breast cancer undergoing breast-conserving surgery--two center experience. Biomed Pap Med Fac Univ Palacky Olomouc Czech Repub, 158, 461-4.

Wang SL, Li YX, Song YW, et al (2009). [Postmastectomy radiotherapy in moderate-and high-risk elderly breast cancer patients]. Zhonghua Zhong Liu Za Zhi, 31, 863-6.

Winzer KJ, Sauerbrei W, Braun M, et al (2010). Radiation therapy and tamoxifen after breast-conserving surgery: updated results of a $2 \times 2$ randomised clinical trial in patients with low risk of recurrence. Eur J Cancer, 46, 95-101.

Yancik R, Wesley MN, Ries LA, et al (2001). Effect of age and comorbidity in postmenopausal breast cancer patients aged 55 years and older. JAMA, 285, 885-92.

Yavas G, Yavas C, Akyurek N (2013). Postmastectomy radiation therapy in locally advanced breast cancer. Exp Oncol, 35, 258-66.

Zhou P, Recht A (2004). Young age and outcome for women with early-stage invasive breast carcinoma. Cancer, 101, 1264-74. 